\section{THE FEATURES OF ADAPTATION THE NEW- BORNS THAT WERE BORN BY A CAESAR SECTION AT GENERAL ANAESTHESIA OF THE WOMAN}

\author{
O.V. Dankov ${ }^{1}$, R. Gurskiy ${ }^{2,3}$, G. Naconechna ${ }^{3,4}$, \\ N. Chalina ${ }^{1,3}$ \\ ${ }^{1}$ Obstetric, ${ }^{2}$ Anaesthetic, ${ }^{3} 3-r d$ Clinical City \\ Hospital, ${ }^{4}$ New-borns, 3-rd Clinical City Hospital, \\ Lviv, Ukraine
}

There were compared the features of the motion of early neonatal adaptation of the new-borns $(n=185)$, that were born by a caesar section at general anaesthesia of the woman. Every third child $(n=62)$, after the implementation of the initial steps of PRN and the estimation of the indexes of the primary adaptation, was put to the breasts in the first $30 \mathrm{~min}$ after the birth. The motion of the early neonatal adaptation of 62 new-borns was compared to its motion in new-borns $(n=123)$, that after the completion of the initial steps of the primary reanimation to the moment of the mother's output from the anaesthesia were transferred to the chamber.

There was found out the substantially better motion of the early neonatal adaptation in the new-borns, that in the first 30 min of life were put to the mother's breasts, in spite of her unconscious state (general anaesthesia), by comparison to the children, that during the first several hours of life were not put to the breasts. The new-borns, that got milk in the operating room, were in the maternity hospital for the shortest period (4-5 days), against 7 days for the children $(p<0,05)$, that for the first time were put to the breasts after the mother's output from the general anaesthesia.

Our observations showed, that mother's stay in the general anaesthesia cannot be the contraindication to the early put of the baby to the breasts.

\section{MANAGEMENT OF THE UPPER POUCH IN NEONATES WITH OESOPHAGEAL ATRESIA: NATIONAL SURVEY ON USE OF REPLOGLE TUBES IN UNITED KINGDOM}

\author{
V. Kolimarala, G. Jawaheer, B. Reda
}
Birmingham Children's Foundation NHS Trust, Birmingham, UK

Aims: The standard of care for the management of the upper oesophageal pouch is low grade suction applied to a Replogle tube. Availability of Replogle tubes and familiarity of staff with them in units admitting neonates with oesophageal atresia in Britain is unknown. The aim of this study was to obtain such data.

Methods: A questionnaire was designed to obtain information relating to the use of Replogle tubes in neonates with oesophageal atresia. Neonatal units in the United Kingdom were contacted by telephone and questionnaire filled in.

Results: 137 neonatal units were contacted. 100\% response rate was obtained. The questionnaire was filled in following a telephone interview with a nurse in $115(83 \%)$ cases and doctor in $23(17 \%)$ cases. $102(74 \%)$ units used a Replogle tube for managing the upper pouch. A 'nasogastric' tube was used instead in 21 units and 2 units, used oral suction only. In the remaining 12 units, it was unclear how the upper pouch was drained. Low flow suction was used in conjunction with Replogle tubes in $87 \%$ of cases. Guidelines on the use of Replogle tubes were available in $40 \%$ of cases. The tube was flushed in $36 \%$ of cases and salivary fluid losses were replaced in $31 \%$ of cases.

Conclusions: The use of Replogle tubes in Britain is not universal. Units which use Replogle tube have varied practices and use of suction is not routine. In a minority of cases, management is suboptimal. An education programme and practice guidelines would be beneficial. 